Article

\title{
Development of an Ionic Liquid-Based Ultrasonic/Microwave-Assisted Simultaneous Distillation and Extraction Method for Separation of Camptothecin, 10-Hydroxycamptothecin, Vincoside-Lactam, and Essential Oils from the Fruits of Camptotheca acuminata Decne
}

\author{
Chunjian Zhao ${ }^{1,2,3}$, Yukun Zhang ${ }^{1,2}$, Chunying $\mathrm{Li}^{1,2, *}$, Xin He ${ }^{1,2}$, Lei Yang ${ }^{1,2}$, Yujie Fu ${ }^{1,2,3}$, \\ Jingjing Zhang ${ }^{1,2}$, Wenyan Zhao ${ }^{1,2}$ and Yuangang $\mathrm{Zu}^{1,2}$ \\ 1 Key Laboratory of Forest Plant Ecology, Ministry of Education, Northeast Forestry University, \\ Harbin 150040, China; zcjsj@163.com (C.Z.); klp14zyk@nefu.edu.cn (Y.Z.); klp13hx@nefu.edu.cn (X.H.); \\ ylnefu@163.com (L.Y.); yujie_fu@163.com (Y.F.); klp15zjj@nefu.edu.cn (J.Z.); klp15zwy@nefu.edu.cn (W.Z.); \\ zuyuangang54@aliyun.com (Y.Z.) \\ 2 State Engineering Laboratory of Bio-Resource Eco-Utilization, Northeast Forestry University, \\ Harbin 150040, China \\ 3 Collaborative Innovation Center for Development and Utilization of Forest Resources, Harbin 150040, China \\ * Correspondence: nefujane@aliyun.com; Tel.: +86-451-8219-0848; Fax: +86-451-8210-2082
}

Academic Editor: Thomas J. J. Müller

Received: 21 September 2016; Accepted: 10 October 2016; Published: 13 October 2016

\begin{abstract}
An ionic liquid-based ultrasonic/microwave-assisted simultaneous distillation and extraction (IL-UMASDE) method for isolating camptothecin (CPT), 10-hydroxycamptothecin (HCPT), vincoside-lactam (VCS-LT), and essential oils (EOs) from Camptotheca acuminata Decne fruits was developed. The important parameters were optimized using single-factor and central composite design experiments. The optimum conditions were $0.75 \mathrm{M}$ 1-octyl-3-methylimidazolium $\left(\left[\mathrm{C}_{8} \mathrm{mim}\right] \mathrm{Br}\right)$ as the extraction solvent, a liquid-solid ratio of $13.7 \mathrm{~mL} / \mathrm{g}$, an extraction time of $33.2 \mathrm{~min}$, a microwave power of $582 \mathrm{~W}$, and a fixed ultrasonic power of $50 \mathrm{~W}$. The yields of CPT, HCPT, and VCS-LT obtained under the optimum conditions were $2.463,0.164$, and $0.297 \mathrm{mg} / \mathrm{g}$, respectively; these are 1.08-, $1.12-$, and 1.04-fold higher, respectively, than those obtained by conventional $55 \%$ ethanol heat reflux extraction (HRE). The extraction time for the equilibrium yields of CPT, HCPT and VCS-LT using IL-UMASDE was $33.6 \%, 58.5 \%, 63.1 \%$, and $66.8 \%$, respectively, less than the corresponding times using IL-MASDE, IL-ultrasonic-assisted extraction (IL-UAE), 55\% ethanol UAE and 55\% ethanol HRE. The yield of EOs obtained using IL-UMASDE was $0.793 \mathrm{mg} / \mathrm{g}$, i.e., 1.31 -fold higher than that obtained by conventional hydrodistillation extraction (HDE). The components of the EOs obtained using IL-UMASDE and HDE were similar. The extraction time for the equilibrium yields of EOs using IL-UMASDE is $33.6 \%, 58.5 \%, 52.6 \%$, and $72.3 \%$ lower than those for IL-MASDE, water-UMASDE, water-MASDE, and HDE, respectively. Compared with other extraction methods, IL-UMASDE gave the highest yields of CPT, HCPT, VCS-LT, and EOs and also had the shortest extraction time. IL-UMASDE is a potential green and highly efficient technique for the extraction of CPT, HCPT, VCS-LT, and EOs from Camptotheca acuminata Decne fruits.
\end{abstract}

Keywords: ultrasonic/microwave-assisted simultaneous distillation and extraction; ionic liquid; essential oil; camptothecin; Camptotheca acuminata 


\section{Introduction}

Camptotheca acuminata Decne is a member of the Nyssaceae family of plants, and is widely distributed in Asia, particularly southern China. The whole plant contains biologically active constituents such as alkaloids [1]. Possessing promising activity of anti-tumor, camptothecin (CPT) first attracted considerable attention globally [2-4]. In succession, a wide range of CPT derivatives have been identified and shown to be effective for the treatment of various cancers [5]. Among these derivatives, 10-hydroxycamptothecin (HCPT) is more potent and less toxic than CPT [6], and has been widely used in experimental and clinical studies [7,8]. In addition, vincoside-lactam (VCS-LT), which has potential antitumor activity [9] and inhibits lipopolysaccharide-induced NO release in primary cultured rat cortical tissue [10], has also been isolated from C. acuminata. The molecular structures of CPT, HCPT, and VCS-LT are shown in Figure 1.

Essential oils (EOs) from higher plants have attracted much attention because of their antibacterial, antifungal, antiviral, insecticidal, and antioxidant activities [11-13]. Recently, except for the alkaloid, essential oils were also found naturally in C. acuminata [14]. Because of the significant pharmacological activities of the alkaloids and EOs from C. acuminata, it is important to develop robust and efficient separation techniques to enable them to be studied in greater detail. However, there has been no report of the simultaneous extraction and separation of alkaloids and EOs from C. acuminata.

Non-volatile CPT, HCPT, and VCS-LT and volatile EOs are currently extracted using separate processes. Heat reflux extraction (HRE) [15], soxhlet extraction [16], homogenation [17], maceration [18], ultrasonic-assisted extraction (UAE), or microwave-assisted extraction (MAE) [19] have been used to extract CPT, HCPT, and VCS-LT. Except in the case of MAE, large amounts of organic, potentially toxic, solvents such as methanol, ethanol, and acetone are used in these extraction methods, resulting in atmospheric pollution and potential health hazards to operators [20]. Environmentally friendly and efficient extraction methods that do not have these disadvantages are therefore needed.

Ionic liquids (ILs) are excellent solvents and have shown great potential in replacing conventional organic solvents in many fields [21]. An IL consists of a large asymmetric organic cation and a smaller inorganic or organic anion. ILs are almost liquid salts at room temperature, and they have high extraction efficiencies. ILs have been widely studied as green, environmentally benign alternatives to traditional solvents [22]. They have high thermal stabilities, negligible vapor pressures, and wide liquid-temperature ranges and are good solvents for polar and non-polar compounds. IL-based UAE [23], MAE [24,25] and simultaneous ultrasonic/microwave-assisted extraction (UMAE) [26] are being increasingly used in separation technology.

Plant EOs can be isolated by traditional hydrodistillation extraction (HDE) [27] or steam distillation extraction $[28,29]$. However, the general application of these traditional techniques is limited because shortcomings such as long extraction times and poor recoveries make them particularly inefficient [30]. In recent days, the isolation of EOs from some plants using microwave-assisted HDE or steam distillation extraction has been investigated [31-33]. Simultaneous distillation extraction (SDE) using the Likens-Nickerson method effectively combines the advantages associated with liquid-liquid and steam distillation extractions and the extraction efficiency and recovery of volatile compounds are higher than those for traditional HRE and steam distillation extraction [34]. However, only EOs could be obtained using above methods.

Based on our previous work $[26,35,36]$, and considering the advantages of ILs, SDE, and UMAE, we developed an IL-based ultrasonic/microwave-assisted simultaneous distillation and extraction (IL-UMASDE) method for synchronous extraction of CPT, HCPT, and VCS-LT and EOs from C. acuminata fruits. In this study, factors with important effects on the yields of CPT, HCPT, VCS-LT, and EOs, such as the IL concentration, liquid-solid ratio, extraction time, and microwave power were studied. Furthermore, the optimum conditions for IL-UMASDE were established using central composite design (CCD) combined with response surface methodology (RSM). The method was compared with conventional extraction methods and its advantages were identified. 
<smiles>[R]c1ccc2nc3c(cc2c1)Cn1c-3cc2c(c1=O)COC(=O)C2(O)CC</smiles>

$\mathrm{R}=\mathrm{H} \quad$ Camptothecin (CPT)

$\mathrm{R}=\mathrm{OH} \quad 10-$ Hydroxycamptothecin (HCPT)

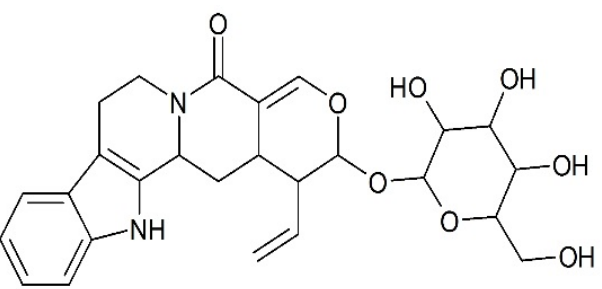

Vincoside-lactam (VCS-LT)

Figure 1. Chemical structures of CPT, HCPT, and VCS-LT.

\section{Experimental}

\subsection{Plant Materials}

C. acuminata fruits were harvested in Jintang county, Sichuan province, China. The fruits were dried in the shade at room temperature, comminuted using a disintegrator (HX-200A, Yongkang Hardware and Medical Instrument Plant, Yongkang, China), passed through a stainless-steel sieve (60-80 mesh), and stored in closed desiccators at $4{ }^{\circ} \mathrm{C}$ until use.

\subsection{Chemicals}

CPT (98\%) and $C_{7}-C_{40}$ saturated alkane mixture standards were purchased from Sigma-Aldrich Inc. (Shanghai, China). An HCPT standard (98\%) was purchased from Wako Pure Chemical Industries, Ltd. (Osaka, Japan). A VCS-LT standard (98\%) was donated by Professor Weiguo Shi, Jiamusi University, China.

$\operatorname{ILs}\left(\left[\mathrm{C}_{2} \mathrm{mim}\right] \mathrm{Br},\left[\mathrm{C}_{4} \mathrm{mim}\right] \mathrm{Br},\left[\mathrm{C}_{6} \mathrm{mim}\right] \mathrm{Br},\left[\mathrm{C}_{8} \mathrm{mim}\right] \mathrm{Br},\left[\mathrm{C}_{10} \mathrm{mim}\right] \mathrm{Br},\left[\mathrm{C}_{4} \mathrm{mim}\right] \mathrm{BF}_{4},\left[\mathrm{C}_{4} \mathrm{mim}\right] \mathrm{HSO}_{4}\right.$, $\left[\mathrm{C}_{4} \mathrm{mim}\right] \mathrm{NO}_{3},\left[\mathrm{C}_{4} \mathrm{mim}\right] \mathrm{Cl},\left[\mathrm{C}_{4} \mathrm{mim}\right] \mathrm{ClO}_{4} ; \mathrm{C}_{2} \mathrm{mim}=1$-ethyl-3-methylimidazolium, $\mathrm{C}_{4} \mathrm{mim}=1$-butyl-3methylimidazolium, $\mathrm{C}_{6} \mathrm{mim}=1$-hexyl-3-methylimidazolium, $\mathrm{C}_{8} \mathrm{mim}=1$-octyl-3-methylimidazolium, $\mathrm{C}_{10}$ mim $=1$-decyl-3-methylimidazolium) were purchased from the Chengjie Chemical Co., Ltd. (Shanghai, China). High-performance liquid chromatography (HPLC) grade acetonitrile was purchased from J\&K Chemical Ltd. (Beijing, China). Deionized water for HPLC was purified using a Milli-Q Water Purification System (Millipore, Billerica, MA, USA). Other reagents were obtained from the Tianjin Kermel Chemical Reagent Co., Ltd. (Tianjin, China). All solutions and samples prepared for analysis were filtered through a $0.45 \mu \mathrm{m}$ nylon membrane (Guangfu Chemical Reagents Co., Tianjin, China).

\subsection{Apparatus}

The UMASDE apparatus consisted of a UMAE system (CW-2000, Shanghai Xintuo Analytical Instrument Technology Co., Ltd., Shanghai, China) connected to a Likens-Nickerson SDE unit (Chaoyue Laboratory Instrument Works Co., Shanghai, China). A schematic diagram of the UMASDE apparatus is shown in Figure 2. The UMAE system can be operated in three modes, i.e., microwave, ultrasonic, and combined microwave/ultrasonic. The UMAE system was operated at a microwave irradiation frequency of $2450 \mathrm{MHz}$ with an output power in the range 10-800 $\mathrm{W}$ and a fixed ultrasonic frequency of $40 \mathrm{kHz}$ with an output power $50 \mathrm{~W}$. The dimensions of the interior cavity of the oven were $430 \times 512 \times 510 \mathrm{~mm}$; the oven was large enough to accommodate a $500 \mathrm{~mL}$ flask. 


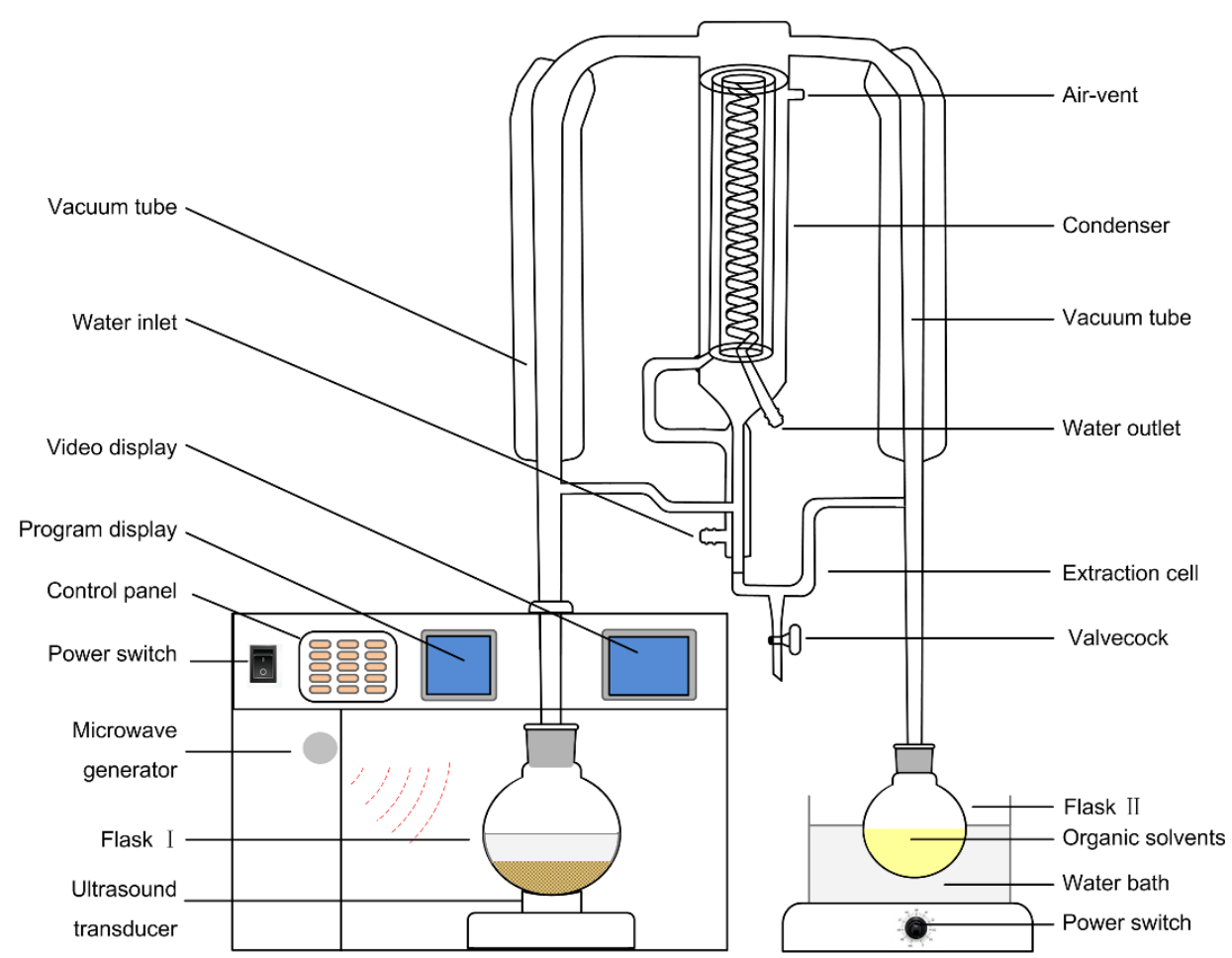

Figure 2. Schematic diagram of UMASDE device.

\subsection{Extraction Procedure}

\subsubsection{Conventional HRE}

A dried, powdered sample $(20 \mathrm{~g})$ was put in a round-bottomed flask and mixed with $55 \%$ ethanol $(300 \mathrm{~mL})$. The flask was placed in a water bath with a reflux device, and extraction was performed for $2 \mathrm{~h}$ at $85^{\circ} \mathrm{C}$.

\subsubsection{UAE}

A dried, powdered sample (20 g) was extracted with 55\% ethanol (300 $\mathrm{mL})$ in the ultrasonic extraction device (KQ-250DB, Kunshan Ultrasonic Instrument Company, Kunshan, China), followed by sonication for $1.5 \mathrm{~h}$ at $40^{\circ} \mathrm{C}$ and $80 \mathrm{kHz}$.

\subsubsection{Conventional HDE}

A dried, powdered sample $(20 \mathrm{~g})$ and water $(300 \mathrm{~mL})$ were placed in a $500 \mathrm{~mL}$ flask connected to a Clevenger apparatus (Chaoyue Laboratory Instrument Works Co., Shanghai, China), for 3 h until no more EOs was obtained. The EOs were separated from the aqueous phase, dried using anhydrous sodium sulfate, and stored at $4{ }^{\circ} \mathrm{C}$ until analysis.

\subsubsection{UMASDE}

Extractions were performed using the UMASDE apparatus described in the 2.3 section (Figure 2) at combined ultrasonic/microwave operation mode. A powdered sample $(20 \mathrm{~g})$ was mixed with an IL or water in a $500 \mathrm{~mL}$ flask (I), and $50 \mathrm{~mL}$ of dichloromethane was put in a $100 \mathrm{~mL}$ flask (II). Flask I was subjected to ultrasonic/microwave treatment in the oven of the UMASDE apparatus and flask II was heated in a water bath at $45^{\circ} \mathrm{C}$. After the extraction, the mixture in flask I was rapidly cooled to room temperature using a cold bath and filtered through a $0.45 \mu \mathrm{m}$ microporous membrane for subsequent HPLC analysis. The organic solvent in flask II was collected and dried using anhydrous sodium sulfate 
overnight. The solvent was removed under reduced pressure to provides the EOs, which were then stored at $4{ }^{\circ} \mathrm{C}$ in the dark until GC-MS analysis.

\subsubsection{MASDE}

Extractions were performed using the UMASDE apparatus at microwave operation mode. The procedure was as described in Section 2.4.4.

\subsection{HPLC Determination of CPT, HCPT, and VCS-LT}

Quantification of for HCPT, CPT, and VCS-LT was performed using HPLC and the development of chromatographic method referred to the references [37,38]. The HPLC system consisted of a HiQ sil-C18 reversed-phase column $(4.6 \mathrm{~mm} \times 250 \mathrm{~mm}, 5 \mu \mathrm{m}$, KYA Technologies Corporation, Tokyo, Japan), a PU 980 pump and 1575 UV detector (Jasco, Tokyo, Japan). The HPLC conditions were as follows: the mobile phase was acetonitrile-water $(25: 75, v / v)$; the column temperature was maintained at $25^{\circ} \mathrm{C}$; the detection wavelength was $254 \mathrm{~nm}$; the flow rate was $1.0 \mathrm{~mL} / \mathrm{min}$; the injection volume was $10 \mu \mathrm{L}$; and the run time was $35 \mathrm{~min}$. Under these conditions, the retention times for HCPT, CPT, and VCS-LT were 10.9, 20.6, and $30.1 \mathrm{~min}$, respectively; HPLC chromatograms of standards and sample are shown in Figure 3.

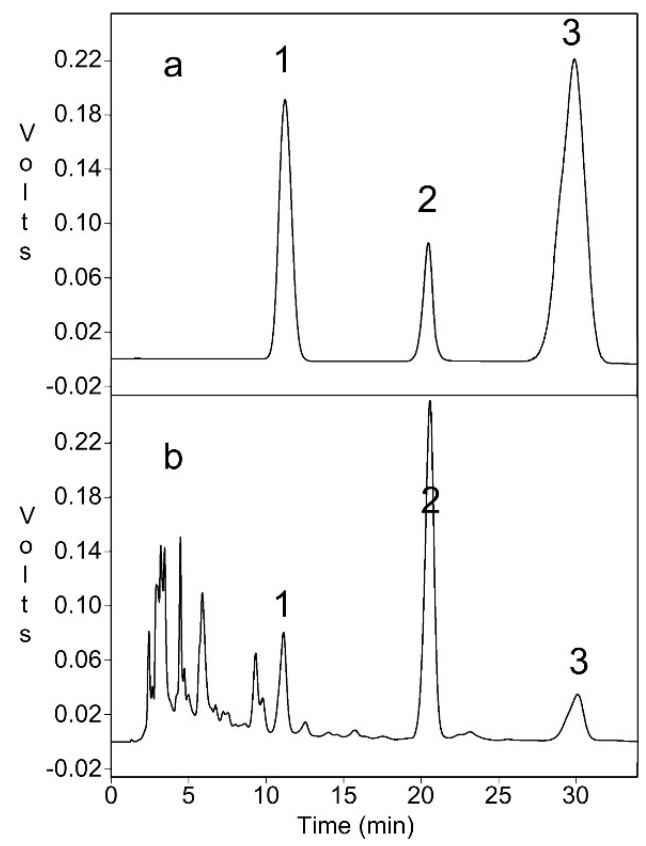

Figure 3. HPLC Chromatograms for CPT, HCPT, and VCS-LT standards (a) and extract from C. acuminata fruits (b). Peak 1 for CPT, Peak 2 for HCPT, Peak 3 for VCS-LT.

\subsection{GC-MS Analysis of EOs}

The EOs were analyzed using a gas chromatography-mass spectrometry (GC-MS) system consisting of an Agilent 7890A gas chromatograph (Agilent Technologies, Inc., Santa Clara, CA, USA)coupled with an Agilent 7000B mass spectrometer (Agilent Technologies, Inc., Santa Clara, CA, USA), with a VF-5MS capillary column (Agilent Technologies, Inc., Santa Clara, CA, USA) ( $30.0 \mathrm{~m} \times 250 \mu \mathrm{m} \times 0.25 \mu \mathrm{m}$ film thickness). The operating conditions were as follows: the injection volume was $1 \mu \mathrm{L}$ at a flow rate of $1.0 \mathrm{~mL} / \mathrm{min}$; split ratio 40:1; the temperature of the injection port was $250{ }^{\circ} \mathrm{C}$ and Helium was used as the carrier gas; the initial column temperature was kept at $50{ }^{\circ} \mathrm{C}$ for $2 \mathrm{~min}$, increased to $280{ }^{\circ} \mathrm{C}$ at a rate of $5{ }^{\circ} \mathrm{C} / \mathrm{min}$ and held for $2 \mathrm{~min}$; the GC-MSD connector temperature was kept at $270{ }^{\circ} \mathrm{C}$; the ion source (E1) temperature was $230{ }^{\circ} \mathrm{C}$; the electron energy was 
$70 \mathrm{eV}$ and the scan scope was 10-600 amu. The percentage composition of the EOs was calculated, using a normalization method, from the GC peak areas. The EOs components were identified by comparing their retention indices and mass spectral fragmentation patterns with those of compounds in the National Institute of Standards and Technology mass spectral library, and comparison with MS data reported in the literature [39].

\subsection{Experimental Design}

\subsubsection{IL-UMASDE Optimization Using RSM}

To achieve efficient extraction of the target compounds, based on the single factor experiment, the interactions between factors were examined. We used $2^{3}$ factorial CCD followed by response contour analysis to optimize the IL-UMASDE operating parameters. Three main influencing factors were selected from the single-factor experiments as independent variables, i.e., the liquid-solid ratio $\left(X_{1}\right)$, extraction time $\left(X_{2}\right)$, and microwave power $\left(X_{3}\right)$. The variables for each factor were set at five levels, i.e., low level $(-1)$, central level $(0)$, and high level $(+1)$ and two outer points corresponding to -1.68 and +1.68 [40]. In the CCD tests, 20 stochastic experiments with six replicates at the center points were used to fit the full quadratic equation model. The general equation is as follows:

$$
Y=\beta_{0}+\sum_{i=1}^{k} \beta_{i} X_{i}+\sum_{i=1}^{k} \beta_{i i} X_{i}^{2}+\sum_{\substack{i=1 \\ i<j}}^{k-1} \sum_{i=2}^{k} \beta_{i j} X_{i} X_{j} \quad(k=3)
$$

where $Y$ is the predicted response variable; $\beta_{0}, \beta_{j}, \beta_{i i}$, and $\beta_{i j}$ are the regression coefficients for the intercept, linearity, square, and interaction terms, respectively; $X_{i}$ and $X_{j}$ are the independent coded variables influencing the response variable $Y$; and $k$ represents the number of variables. The dependent variables are the yields of CPT, HCPT, and VCS-TL. The actual and coded levels of the independent variables used in the experimental design are shown in Table 1. All the experiments were repeated three times and the yields were given as average values.

Table 1. Experimental conditions used in the central composite design analysis and the corresponding measured responses.

\begin{tabular}{|c|c|c|c|c|c|c|c|}
\hline \multirow{2}{*}{ Runs } & \multicolumn{3}{|c|}{ Factors } & \multicolumn{4}{|c|}{ Yields (mg/g) } \\
\hline & $X_{1}(\mathrm{~mL} / \mathrm{g})^{a}$ & $X_{2}(\min )^{b}$ & $X_{3}(W)^{c}$ & CPT & HCPT & VCS-LT & EOs \\
\hline 1 & $1(16)$ & $-1(20)$ & $-1(350)$ & 1.267 & 0.115 & 0.181 & 0.423 \\
\hline 2 & $-1(8)$ & $-1(20)$ & $1(650)$ & 1.303 & 0.091 & 0.192 & 0.405 \\
\hline 3 & $-1(8)$ & $-1(20)$ & $-1(350)$ & 1.187 & 0.084 & 0.145 & 0.388 \\
\hline 4 & $1(16)$ & $1(40)$ & $1(650)$ & 2.154 & 0.154 & 0.274 & 0.647 \\
\hline 5 & $1(16)$ & $1(40)$ & $-1(350)$ & 1.328 & 0.108 & 0.186 & 0.415 \\
\hline 6 & $-1(8)$ & $1(40)$ & $-1(350)$ & 1.099 & 0.062 & 0.167 & 0.361 \\
\hline 7 & $0(12)$ & $0(30)$ & $0(500)$ & 2.445 & 0.160 & 0.292 & 0.841 \\
\hline 8 & $1(16)$ & $-1(20)$ & $1(650)$ & 1.428 & 0.102 & 0.229 & 0.481 \\
\hline 9 & $0(12)$ & $0(30)$ & $0(500)$ & 2.463 & 0.164 & 0.297 & 0.790 \\
\hline 10 & $-1(8)$ & $1(40)$ & $1(650)$ & 1.532 & 0.084 & 0.236 & 0.459 \\
\hline 11 & $0(12)$ & $0(30)$ & $0(500)$ & 2.353 & 0.157 & 0.286 & 0.805 \\
\hline 12 & $0(12)$ & $0(30)$ & $0(500)$ & 2.286 & 0.153 & 0.281 & 0.738 \\
\hline 13 & $-1.68(5.27)$ & $0(30)$ & $0(500)$ & 1.184 & 0.031 & 0.157 & 0.379 \\
\hline 14 & $0(12)$ & $0(30)$ & $-1.68(247.73)$ & 1.221 & 0.117 & 0.142 & 0.392 \\
\hline 15 & $0(12)$ & $-1.68(13.18)$ & $0(500)$ & 1.094 & 0.079 & 0.163 & 0.339 \\
\hline 16 & $0(12)$ & $0(30)$ & $0(500)$ & 2.385 & 0.149 & 0.295 & 0.778 \\
\hline 17 & $0(12)$ & $1.68(46.82)$ & $0(500)$ & 1.657 & 0.118 & 0.243 & 0.501 \\
\hline 18 & $0(12)$ & $0(30)$ & $1.68(752.27)$ & 2.115 & 0.148 & 0.253 & 0.657 \\
\hline 19 & $0(12)$ & $0(30)$ & $0(500)$ & 2.296 & 0.154 & 0.276 & 0.789 \\
\hline 20 & $1.68(18.73)$ & $0(30)$ & $0(500)$ & 1.739 & 0.092 & 0.256 & 0.529 \\
\hline
\end{tabular}

${ }^{\mathrm{a}} \mathrm{X}_{1}$ is the liquid-solid ratio $(\mathrm{mL} / \mathrm{g}){ }^{\mathrm{b}} \mathrm{X}_{2}$ is the extraction time $(\mathrm{min}){ }^{\mathrm{c}} \mathrm{X}_{3}$ is the microwave power $(\mathrm{W})$. 


\subsubsection{Statistical Analysis}

The experimental data from IL-UMASDE tests designed using CCD were analyzed statistically using a response surface analysis procedure (Design-Expert 7.0.0 Trial, State-Ease, Inc., Minneapolis, MN, USA) to determine and assess the statistical significance of the equations. The fit quality of the polynomial model equation was expressed by the regression coefficient $\left(R^{2}\right)$ and the lack of fit, the Fisher test value ( $F$-value) and their interactions were estimated using analysis of variance (ANOVA). The adequacy of the fitted model was evaluated by comparing the actual and predicted values. The optimum values for three variables (liquid-solid ratio: $8-16 \mathrm{~mL} / \mathrm{g}$, extraction time: 20-40 min and microwave power: 350-650 W) were obtained by statistical analysis (DE software, 8.01 version, Stat-Ease, Inc., Minneapolis, MN, USA) [26].

\section{Results and Discussion}

\subsection{Choosing an Appropriate IL}

Previous studies on the use of ILs as solvents for biomaterials have shown that imidazolium ILs can dissolve various types of biomacromolecule [41]. It was also reported that imidazolium ILs containing a carboxylic acid anion have low melting points, low viscosities, and high hydrogen-bonding-acceptor abilities, and these properties increase the dissolution of plant matter [42]. The IL structure affects its physical and chemical properties, which might affect the extraction efficiencies of target analytes. The anion is considered to be the factor that most influences the properties of ILs [43]. 1-Butyl-3-methylimidazolium-based ILs with the same concentrations but with six different anions $\left(\mathrm{Br}^{-}, \mathrm{Cl}^{-}, \mathrm{BF}_{4}^{-}, \mathrm{ClO}_{4}^{-}, \mathrm{HSO}_{4}^{-}\right.$, and $\left.\mathrm{NO}_{3}{ }^{-}\right)$were used in UMASDE to identify the best IL and assess its performance in the IL-UMASDE of CPT, HCPT, VCS-LT, and EOs from Camptotheca acuminata fruits. The results (Figure 4a) show that the yields of CPT, HCPT, and VCS-LT were anion-dependent and the yields obtained using $\left[\mathrm{C}_{4} \mathrm{mim}\right] \mathrm{Br}$ were higher than those using other ILs. The yield primarily depends on the ability of the IL to dissolve cellulose in plant cells. The ability of an IL to dissolve cellulose depends on its ability to disrupt the extensive network of inter- and intra-molecular hydrogen bonds and form new hydrogen bonds between carbohydrate hydroxyl protons and the IL anions; it also depends on the strengths of interactions such as $\pi-\pi$ and ion/charge-charge interactions [44-46]. However, there were no significant differences among the EOs yields $(p>0.05) . \mathrm{Br}^{-}$was therefore chosen as the IL anion for extracting CPT, HCPT, VCS-LT, and EOs from Camptotheca acuminata fruits.

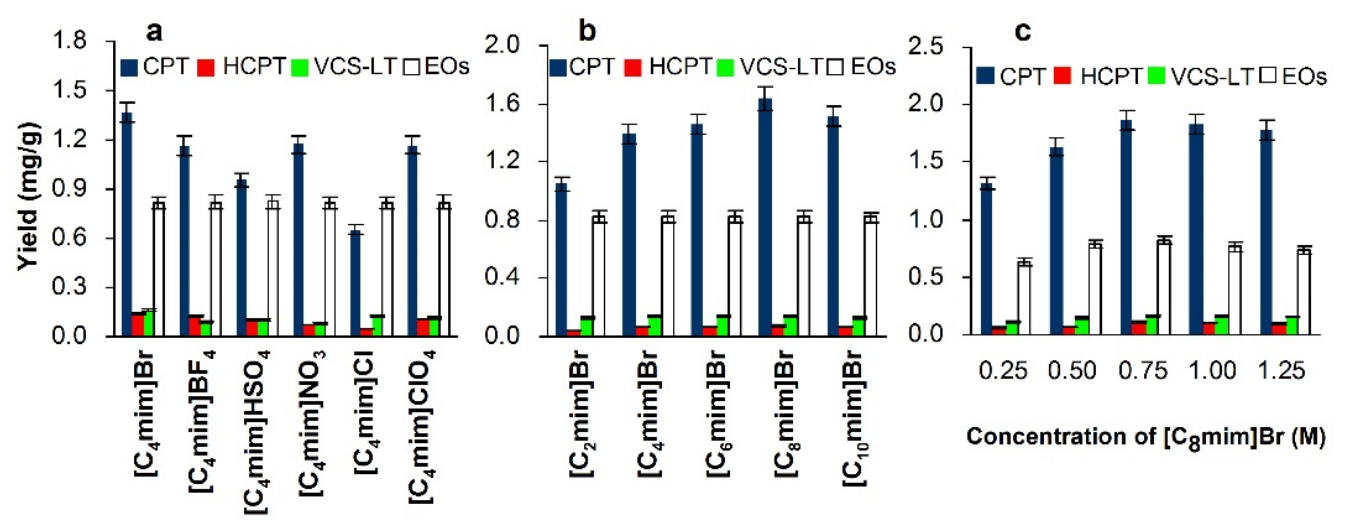

Figure 4. Effects of IL anions (a) and cations (b) and concentration of $\left[\mathrm{C}_{8} \mathrm{mim}\right] \mathrm{Br}(\mathbf{c})$ on yields of CPT, HCPT, VCS-LT, and EOs.

The alkyl chain length affects the water miscibility of an IL, and this can affect the extraction efficiency [47]. 1-Alkyl-3-methylimidazolium ILs containing the same anion, i.e., $\mathrm{Br}^{-}$, but with alkyl chains of different lengths (ethyl to decyl) in the cation, were used in UMASDE to study the effect of the alkyl chain length. The results (Figure $4 \mathrm{~b}$ ) show that the cation alkyl chain length significantly 
affects the yields of the target compounds. This may be related to the solubilities of alkaloids and glycoside compounds in the extraction solvent. The yields of CPT and HCPT increased with increasing alkyl chain length from ethyl to octyl, but when the alkyl chain length was more than eight carbons, the yields of CPT and HCPT decreased. Thus, the highest yields of CPT and HCPT were obtained using $\left[\mathrm{C}_{8} \mathrm{mim}\right] \mathrm{Br}$. The highest VCS-LT yield was obtained using $\left[\mathrm{C}_{4} \mathrm{mim}\right] \mathrm{Br}$, but the yield was not significantly different from that using $\left[\mathrm{C}_{8} \mathrm{mim}\right] \mathrm{Br}(p>0.05)$. In addition, the EOs yields were no significant differences $(p>0.05)$ using the ILs with alkyl chains of different lengths. Based on these results, $\left[\mathrm{C}_{8} \mathrm{mim}\right] \mathrm{Br}$ was considered to be the best IL for use in further experiments.

\subsection{Optimization of IL Concentration}

The effect of the $\left[\mathrm{C}_{8} \mathrm{mim}\right] \mathrm{Br}$ solution concentration (from 0.25 to $1.25 \mathrm{M}$ ) on the yields of target analytes was studied. The results are shown in Figure 4c. It can be clearly seen that the yields of CPT, HCPT, VCS-LT, and EOs increased greatly with increasing concentration from 0.25 to $0.75 \mathrm{M}$. This may be because the amount of dissolved cellulose increased with increasing of $\left[\mathrm{C}_{8} \mathrm{mim}\right] \mathrm{Br}$ concentration; this would enhance the penetrability of cell walls resulting in enhancement of the extraction capacity of the solvent. A higher IL concentration also enables efficient absorption and transfer of microwave energy [48], therefore microwave absorption and microwave conversion both increase, resulting in increased yields of CPT, HCPT, VCS-LT, and EOs. However, with further increases in the $\left[\mathrm{C}_{8} \mathrm{mim}\right] \mathrm{Br}$ solution from 0.75 to $1.25 \mathrm{M}$, slight decreases in the yields of CPT, HCPT, VCS-LT, and EOs were observed. This may be because the increasing viscosity of the IL solution with increasing concentration resulted in poor permeability and diffusion, making it difficult for the IL to infiltrate into the plant tissue, leading to lower yields of the target compounds. Based on all the above results, $0.75 \mathrm{M}$ $\left[\mathrm{C}_{8} \mathrm{mim}\right] \mathrm{Br}$ was identified as the most appropriate solvent for use in subsequent experiments.

\subsection{Optimization of Single Extraction Condition}

Single-factor experiments were performed in which one factor was changed, while the other factors were fixed. Many factors affect the yields of the target compounds, including the liquid-solid ratio, extraction time, and microwave power. The results of the single-factor experiments are shown in Figure 5.

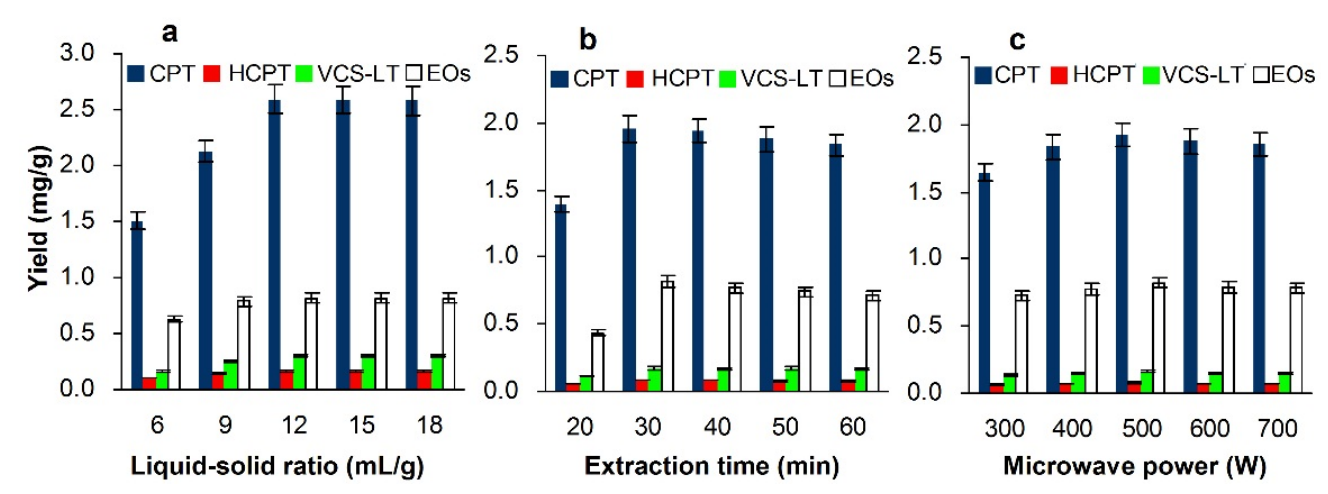

Figure 5. Effects of liquid-solid ratio (a); extraction time (b); and microwave power (c) on yields of CPT, HCPT, VCS-LT, and EOs.

\subsubsection{Effect of Liquid-Solid Ratio}

The liquid-solid ratio has an important effect on the yields of the target compounds. Excess solvent can complicate the experiment and produce unnecessary waste, but insufficient solvent results in incomplete extraction of the targets. Figure 5a shows that the yields of CPT, HCPT, VCS-LT, and EOs significantly increased with increasing liquid-solid ratio up to $12 \mathrm{~mL} / \mathrm{g}$. Within a certain range, increasing the liquid-solid ratio resulted in full immersion of the sample in the solvent; this increased 
mass transfer and higher yields of the target compounds were obtained. However, the yields of the target compounds did not improve greatly when the liquid-solid ratio was further increased. A liquid-solid ratio of $12 \mathrm{~mL} / \mathrm{g}$ was therefore used for further optimization studies.

\subsubsection{Effect of Extraction Time}

From Figure 5b, when the extraction time was increased from 20 to $30 \mathrm{~min}$, the yields of CPT, HCPT, VCS-LT, and EOs increased greatly. However, when the time was more than $30 \mathrm{~min}$, the yields of CPT, HCPT, VCS-LT, and EOs decreased slightly. This is probably because prolonged heating leads to thermal decomposition of the three non-volatile target compounds and volatilization of the EOs, leading to the decreased yields [49]. Based on these results, $30 \mathrm{~min}$ was used for subsequent experiments.

\subsubsection{Effect of Microwave Power}

Optimization of the microwave power is crucial in ensuring efficient extraction, because the microwave energy significantly affects molecular interactions between the target compounds and ILs. Figure $5 \mathrm{c}$ shows that the yields of CPT, HCPT, VCS-LT, and EOs increased rapidly with increasing microwave power from 300 to $500 \mathrm{~W}$. The yields of the target compounds decreased slightly at microwave powers higher than $500 \mathrm{~W}$. A microwave power of $500 \mathrm{~W}$ was therefore used for further optimization experiments.

Based on the above experiments, the optimum IL-UMASDE conditions were $0.75 \mathrm{M}\left[\mathrm{C}_{8} \mathrm{mim}\right] \mathrm{Br}$ as the extraction solvent, a liquid-solid ratio of $12 \mathrm{~mL} / \mathrm{g}$, an extraction time of $30 \mathrm{~min}$, and a microwave power of $500 \mathrm{~W}$.

\subsection{Optimization of IL-UMASDE}

\subsubsection{RSM and Model Fit}

Based on the results of the single-factor experiments, the interactions among the liquid-solid ratio, extraction time, and microwave power were studied using CCD combined with RSM. The experimental conditions and yields of CPT, HCPT, VCS-LT, and EOs for each experiment are shown in Table 1. The contour plots for interactions among liquid-solid ratio, extraction time, and microwave power are shown in Figure 6.

The statistical significance of the model and factors were evaluated using ANOVA F-test at $99 \%$ confidence. The ANOVA results for the quadratic model are shown in Table 2.

The data in Table 2 show that, according to the software analysis, acceptable determination coefficients $\left(R^{2}=0.9852,0.9762,0.9787\right.$, and 0.9811 for CPT, HPCT, VCS-LT, and EOs, respectively), a high significance level for the model $(p<0.01)$ and an insignificant lack of fit $(p>0.01)$ were obtained. These results indicate that the model was precise and applicable to the yields of CPT, HCPT, VCS-LT and EOs using IL-UMASDE. The larger F-value and smaller $p$-value show that the corresponding model terms were more significant. The results from Table 2 also show the significance of the linear terms, quadratic terms, and interaction terms. A second-order polynomial model was used to express the yields of CPT, HCPT, VCS-LT, and EOs using the following equations:

$$
\begin{gathered}
Y_{C P T}=-5.773+0.425 X_{1}+0.165 X_{2}+9.338 \times 10^{-3} X_{3}+2.019 \times 10^{-3} X_{1} X_{2}+ \\
9.125 \times 10^{-5} X_{1} X_{3}+8.183 \times 10^{-5} X_{2} X_{3}-2.060 X_{1}{ }^{2}-3.600 \times 10^{-3} X_{2}{ }^{2}-1.140 X_{3}{ }^{2} \\
Y_{H C P T}=-0.305+4.555 \times 10^{-2} X_{1}+6.145 \times 10^{-3} X_{2}+1.714 \times 10^{-4} X_{3}+2.313 \times 10^{-4} X_{1} X_{2}+ \\
8.333 \times 10^{-7} X_{1} X_{3}+6.167 \times 10^{-6} X_{2} X_{3}-2.006 \times 10^{-3} X_{1}{ }^{2}-1.901 \times 10^{-4} X_{2}{ }^{2}-3.106 \times 10^{-7} X_{3}{ }^{2} \\
Y_{V C S-L T}=-0.712+4.659 \times 10^{-2} X_{1}+1.729 \times 10^{-2} X_{2}+1.387 \times 10^{-3} X_{3}-5.000 \times 10^{-5} X_{1} X_{2}+ \\
4.167 \times 10^{-6} X_{1} X_{3}+5.167 \times 10^{-6} X_{2} X_{3}-1.739 \times 10^{-3} X_{1}^{2}-2.907 \times 10^{-4} X_{2}{ }^{2}-1.378 \times 10^{-6} X_{3}{ }^{2}
\end{gathered}
$$




$$
\begin{gathered}
Y_{E O S}=-2.251+0.159 X_{1}+6.620 \times 10^{-2} X_{2}+3.504 \times 10^{-3} X_{3}+4.054 \times 10^{-4} X_{1} X_{2}+ \\
3.654 \times 10^{-5} X_{1} X_{3}+2.130 \times 10^{-5} X_{2} X_{3}-7.415 \times 10^{-3} X_{1}{ }^{2}-1.306 \times 10^{-3} X_{2}^{2}-4.167 \times 10^{-6} X_{3}^{2}
\end{gathered}
$$

where $Y_{C P T}, Y_{H C P T}, Y_{V C S-L T}$, and $Y_{E O s}$ are yields of CPT, HCPT, VCS-LT, and EOs, respectively; $X_{1}$ is the liquid-solid ratio $(\mathrm{mL} / \mathrm{g}), X_{2}$ is the extraction time $(\mathrm{min})$ and $X_{3}$ is the microwave power $(\mathrm{W})$.
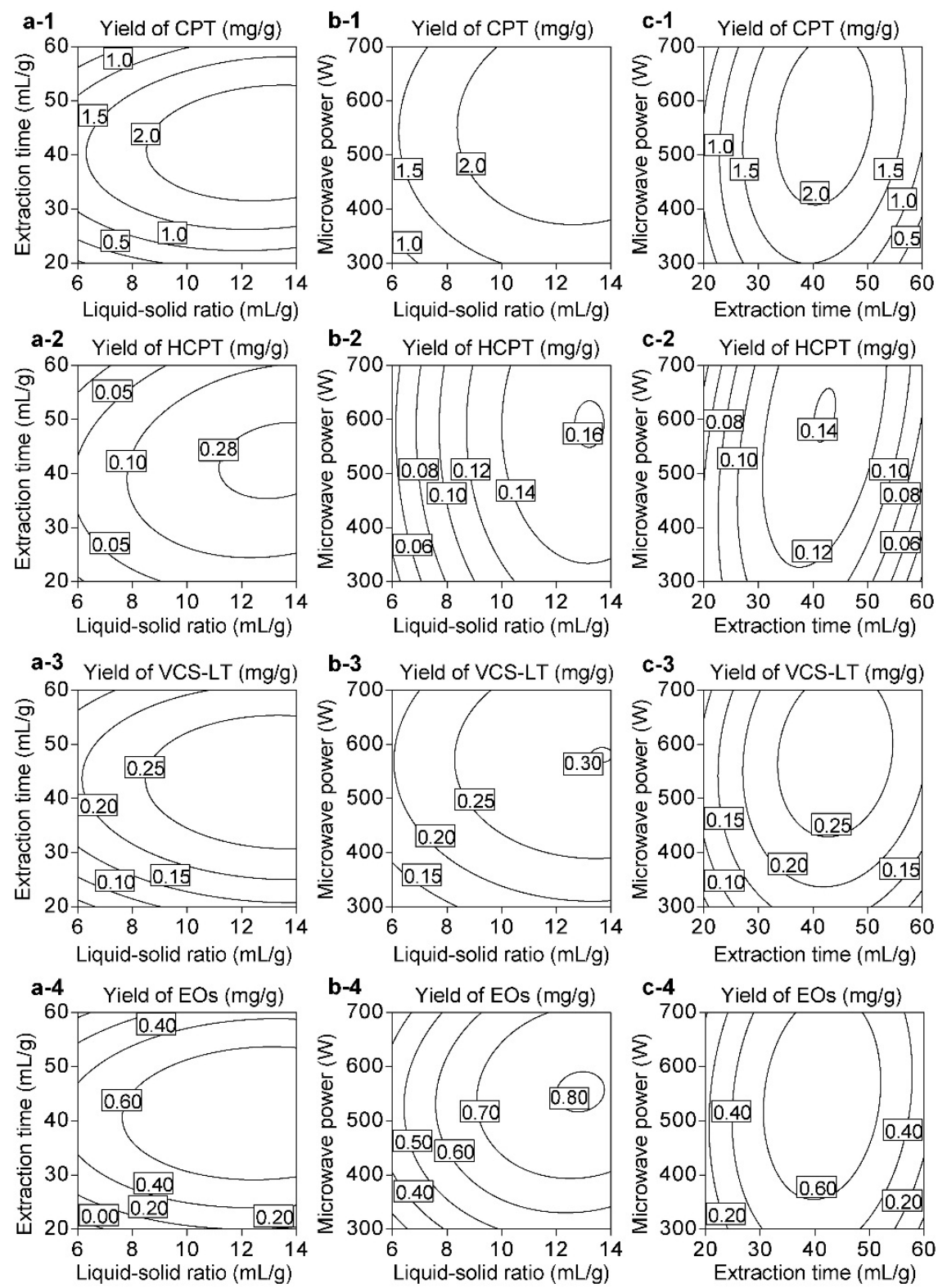

Figure 6. Contour plots for extraction of CPT, HCPT, VCS-LT, and EOs using IL-UMASDE method: effect of liquid-solid ratio and extraction time on yields of CPT (a-1); HCPT (a-2); VCS-LT (a-3); and EOs (a-4); effect of liquid-solid ratio and microwave power on yields of CPT (b-1); HCPT (b-2); VCS-LT (b-3); and EOs (b-4); and effect of extraction time and microwave power on yields of CPT (c-1); HCPT (c-2); VCS-LT (c-3); and EOs (c-4). 
Table 2. ANOVA of the response surface quadratic model for the yields of CPT, HCPT, VCS-LT, and EOs.

\begin{tabular}{|c|c|c|c|c|c|c|c|c|c|c|c|c|c|c|c|c|c|}
\hline \multirow[b]{2}{*}{ Source a } & \multirow[b]{2}{*}{ DF } & \multicolumn{4}{|c|}{ CPT } & \multicolumn{4}{|c|}{ HCPT } & \multicolumn{4}{|c|}{ VCS-LT } & \multicolumn{4}{|c|}{ EO } \\
\hline & & $\begin{array}{l}\text { Sum of } \\
\text { Square }\end{array}$ & $\begin{array}{c}\text { Mean } \\
\text { Aquare }\end{array}$ & $F$ Value & Value $^{b}$ & $\begin{array}{l}\text { Sum of } \\
\text { Squares }\end{array}$ & $\begin{array}{c}\text { Mean } \\
\text { Aquare }\end{array}$ & $F$ Value & $p$-Value ${ }^{\mathrm{b}}$ & $\begin{array}{l}\text { Sum of } \\
\text { Square }\end{array}$ & $\begin{array}{c}\text { Mean } \\
\text { Aquare }\end{array}$ & $F$ Value & -Value ${ }^{b}$ & $\begin{array}{l}\text { Sum of } \\
\text { Square }\end{array}$ & $\begin{array}{c}\text { Mean } \\
\text { Aquare }\end{array}$ & $F$ Value & alue ${ }^{b}$ \\
\hline Model & 9 & 5.09 & 0.57 & 66.67 & $0.000^{++}$ & $2.63 \times 10^{-2}$ & $2.93 \times 10^{-3}$ & 41.03 & $0.000^{++}$ & $5.67 \times 10^{-2}$ & $6.30 \times 10^{-3}$ & 45.85 & $0.000^{++}$ & 0.59 & $6.57 \times 10^{-2}$ & 51.89 & $0.000^{++}$ \\
\hline$X_{1}$ & 1 & 1.58 & 1.58 & .56 & $0.000^{++}$ & $1.84 \times 10^{-2}$ & $1.84 \times 10^{-2}$ & 257.45 & $0.000^{++}$ & $1.72 \times 10^{-2}$ & $1.72 \times 10^{-2}$ & 125.24 & $0.000^{++}$ & 0.19 & 0.19 & 147.09 & $0.000^{++}$ \\
\hline $\begin{array}{l}X_{2} \\
\end{array}$ & 1 & $8.99 \times 10^{-2}$ & $8.99 \times 10^{-2}$ & 10.59 & 0.010 & $1.74 \times 10^{-5}$ & $1.74 \times 10^{-5}$ & 0.24 & 0.633 & $3.58 \times 10^{-3}$ & $3.58 \times 10^{-3}$ & 26.08 & $0.001^{++}$ & $6.16 \times 10^{-3}$ & $6.16 \times 10^{-3}$ & 4.87 & 0.055 \\
\hline$X_{3}$ & 1 & 0.36 & 0.36 & 42.97 & $0.000^{++}$ & $6.29 \times 10^{-4}$ & $6.29 \times 10^{-4}$ & 8.82 & 0.016 & $9.12 \times 10^{-3}$ & $9.12 \times 10^{-3}$ & 66.42 & $0.000^{++}$ & $2.51 \times 10^{-2}$ & $2.51 \times 10^{-2}$ & 19.87 & $0.002^{++}$ \\
\hline$X_{1} X_{2}$ & 1 & $5.22 \times 10^{-2}$ & $5.22 \times 10^{-2}$ & 6.15 & 0.035 & $6.85 \times 10^{-4}$ & $6.85 \times 10^{-4}$ & 9.60 & 0.013 & $3.20 \times 10^{-5}$ & $3.20 \times 10^{-5}$ & 0.23 & 0.641 & $2.10 \times 10^{-3}$ & $2.10 \times 10^{-3}$ & 1.66 & 0.230 \\
\hline$X_{1} X_{3}$ & 1 & $2.40 \times 10^{-2}$ & $2.40 \times 10^{-2}$ & 2.83 & 0.127 & $2.00 \times 10^{-6}$ & $2.00 \times 10^{-6}$ & 0.03 & 0.871 & $5.00 \times 10^{-5}$ & $5.00 \times 10^{-5}$ & 0.36 & 0.561 & $3.84 \times 10^{-3}$ & $3.84 \times 10^{-3}$ & 3.04 & 0.115 \\
\hline$X_{2} X_{3}$ & 1 & 0.12 & 0.12 & 14.20 & $0.004^{++}$ & $6.85 \times 10^{-4}$ & $6.85 \times 10^{-4}$ & 9.60 & 0.013 & $4.81 \times 10^{-4}$ & $4.81 \times 10^{-4}$ & 3.50 & 0.094 & $8.17 \times 10^{-3}$ & $8.17 \times 10^{-3}$ & 6.46 & 0.032 \\
\hline$X_{1}^{2}$ & 1 & 1.56 & 1.56 & 184.34 & $0.000^{++}$ & $1.48 \times 10^{-2}$ & $1.48 \times 10^{-2}$ & 208.01 & $0.000^{++}$ & $1.12 \times 10^{-2}$ & $1.12 \times 10^{-2}$ & 81.19 & $0.000^{++}$ & 0.20 & 0.20 & 160.19 & $0.000^{++}$ \\
\hline$X_{2}^{2}$ & 1 & 1.87 & 1.87 & & & $5.20 \times 10^{-3}$ & $5.20 \times 10^{-3}$ & 72.99 & $0.000^{++}$ & $1.22 \times 10^{-2}$ & $1.22 \times 10^{-2}$ & 88.57 & & 0.25 & 0.25 & 194.12 & $0.000^{++}$ \\
\hline$x_{3}^{2}$ & 1 & 0.95 & 0.95 & 111.72 & $0.000^{++}$ & $7.04 \times 10^{-4}$ & $7.04 \times 10^{-4}$ & 9.87 & 0.012 & $1.38 \times 10^{-2}$ & $1.38 \times 10^{-2}$ & 100.82 & $0.000^{++}$ & 0.13 & 0.13 & 100.02 & $0.000^{++}$ \\
\hline Residua & 9 & $64 \times 10^{-2}$ & $8.49 \times 10^{-3}$ & & & $6.42 \times 10^{-4}$ & $7.13 \times 10^{-5}$ & & & $1.24 \times 10^{-3}$ & $1.37 \times 10^{-4}$ & & & $1.14 \times 10^{-2}$ & $1.27 \times 10^{-3}$ & & \\
\hline Lack of Fit & 5 & $5.19 \times 10^{-2}$ & $1.04 \times 10^{-2}$ & 1.70 & 0.314 & $5.64 \times 10^{-4}$ & $1.13 \times 10^{-4}$ & 5.82 & 0.057 & $9.10 \times 10^{-4}$ & $1.82 \times 10^{-4}$ & 2.23 & 0.229 & $5.79 \times 10^{-3}$ & $1.16 \times 10^{-3}$ & 0.83 & 0.589 \\
\hline Pure Error & 4 & $2.45 \times 10^{-2}$ & $6.11 \times 10^{-3}$ & & & $7.75 \times 10^{-5}$ & $1.94 \times 10^{-5}$ & & & $3.27 \times 10^{-4}$ & $8.16 \times 10^{-5}$ & & & $5.60 \times 10^{-3}$ & $1.40 \times 10^{-3}$ & & \\
\hline $\begin{array}{c}\text { Cor Total } \\
R^{2}\end{array}$ & 19 & $\begin{array}{c}5.17 \\
0.9852\end{array}$ & & & & $\begin{array}{c}2.73 \times 10^{-2} \\
0.9762\end{array}$ & & & & $\begin{array}{c}5.82 \times 10^{-2} \\
0.9787\end{array}$ & & & & $\begin{array}{c}0.60 \\
0.9811\end{array}$ & & & \\
\hline
\end{tabular}

${ }^{a} X_{1}$ is the liquid-solid ratio $(\mathrm{mL} / \mathrm{g}), X_{2}$ is the extraction time $(\mathrm{min}), X_{3}$ is the microwave power $(\mathrm{W}){ }^{\mathrm{b}++}$ is expressed as significant at $p<0.01$. 


\subsubsection{Validation of the Optimum Extraction Conditions}

The optimum extraction conditions (independent variables) obtained using the DE software were as follows: $0.75 \mathrm{M}\left[\mathrm{C}_{8} \mathrm{mim}\right] \mathrm{Br}$ as extraction solvent, extraction time $33.2 \mathrm{~min}$, liquid-solid ratio $13.7 \mathrm{~mL} / \mathrm{g}$ and microwave power $582 \mathrm{~W}$. The predicted yields under the above conditions were $2.475 \mathrm{mg} / \mathrm{g}$ for CPT, $0.163 \mathrm{mg} / \mathrm{g}$ for HCPT, $0.304 \mathrm{mg} / \mathrm{g}$ for VCS-LT, and $0.804 \mathrm{mg} / \mathrm{g}$ for EOs. The suitability of the model equations for predicting the response values was confirmed by performing a verification experiment under these optimized conditions. The actual yields of CPT, HCPT, VCS-LT, and EOs were $2.463,0.164,0.297$, and $0.793 \mathrm{mg} / \mathrm{g}$, respectively. The CPT, HCPT, VCS-LT, and EOs yields obtained using IL-UMASDE were close to the predicted values and showed low deviations $(<1.2 \%)$, demonstrating the reliability of the RSM models.

\subsection{Comparison of Different Extraction Methods}

The effect of different extraction methods on the yields of CPT, HCPT, VCS-LT, and EOs are shown in Figure 7. From Figure 7a-c, it can be seen that IL-UMASDE is a better method than IL-MASDE, IL-UAE, 55\% ethanol UAE and conventional 55\% ethanol HRE techniques in terms of the CPT, HCPT, and VCS-LT yields and time consumption. The yields of CPT, HCPT, and VCS-LT obtained using IL-UMASDE were 1.08-, 1.12-, and 1.04-fold higher than those obtained using 55\% ethanol HRE. The extraction time taken to reach the equilibrium yields of CPT, HCPT and VCS-LT using IL-UMASDE was only $33.2 \mathrm{~min}$, which is $33.6 \%, 58.5 \%, 63.1 \%$, and $66.8 \%$ lower than those for IL-MASDE, IL-UAE, 55\% ethanol UAE and conventional 55\% ethanol HRE, respectively. The yields obtained using IL-UMASDE are higher mainly because the IL dissolves the cellulose in the plant cell walls and the target compounds are highly soluble in the IL. In addition, the ultrasonic/microwave combination breaks the plant cells, which also accelerates the release of CPT, HCPT, and VCS-LT from the matrix; it also increases the molecular motion of the extraction solvent, which increases mass transfer, leading to higher yields of the target compounds.
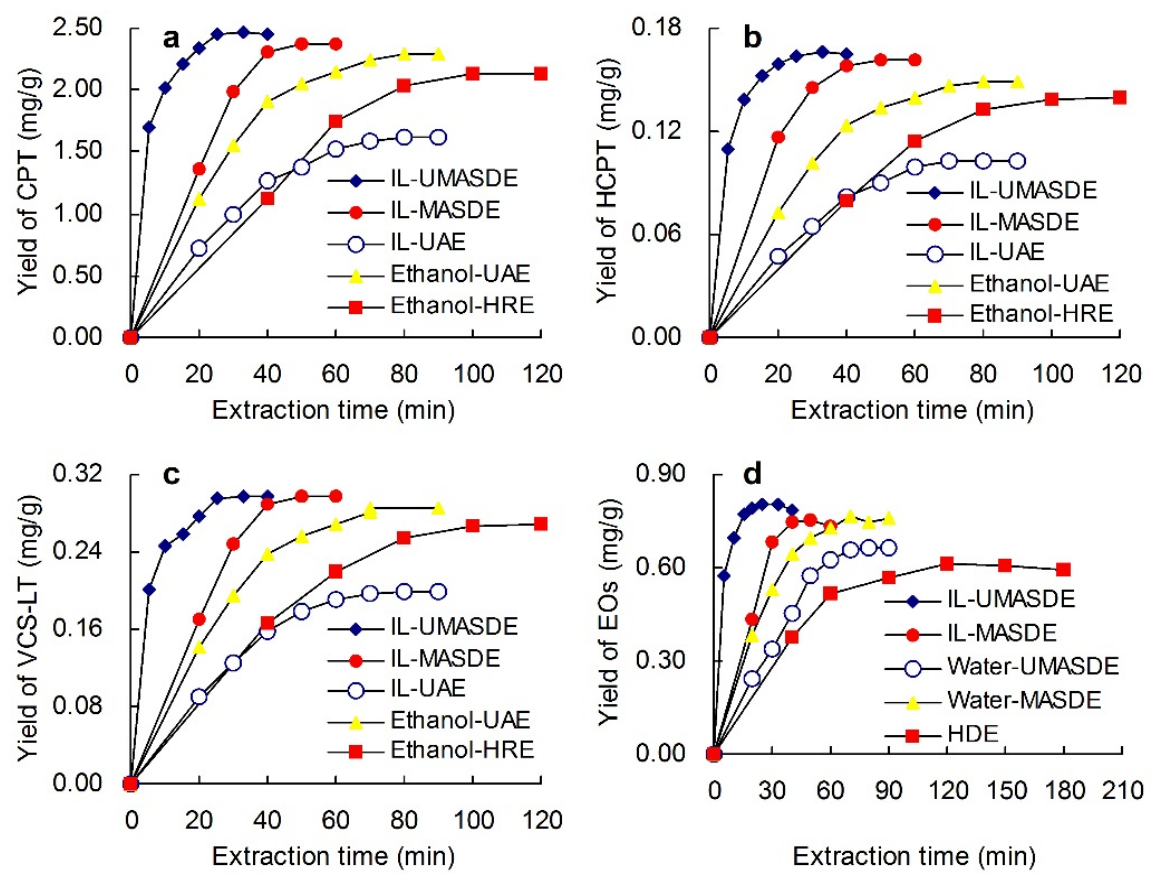

Figure 7. Comparison of different methods for extraction of CPT, HCPT, VCS-LT, and EOs from C. acuminata fruits. Effect of extraction time on Yield CPT (a), HCPT (b), BCS-LT (c), and Eos (d).

The variations in the EOs yield with extraction time using different methods are shown in Figure 7d. The yield of EOs using IL-UMASDE was $0.793 \mathrm{mg} / \mathrm{g}$, which is 1.07-, 1.21-, 1.05-, and 1.31-fold 
higher than those obtained using IL-MASDE, water-UMASDE, water-MASDE, and HDE, respectively. The extraction time (33.2 min) of EOs using IL-UMASDE is $33.6 \%, 58.5 \%, 52.6 \%$, and $72.3 \%$ lower than those for IL-MASDE, water-UMASDE, water-MASDE, and HDE, respectively. The extraction efficiency of IL-UMASDE is higher mainly because the ultrasonic/microwave combination breaks the plant cells and the IL dissolves the cellulose in the plant cell walls, which accelerates the release of EOs from the matrix. GC-MS was used to identify the chemical compositions of EOs and the results are shown in Table 3. 22 components from the EOs obtained using conventional HDE were identified, accounting for $90.03 \%$ of the total EOs constituents. 25 components from the EOs obtained using IL-UMASDE were identified, accounting for $90.11 \%$ of the total EOs constituents. Similarity of EOs constituents using above two methods is $95.3 \%$ by "Similarity Evaluation System for Chromatographic Fingerprint of TCM" software (Pharmacopoeia Commission of the People's Republic of China, 2004). These results show that the ultrasonic/microwave combination accelerated the extraction process, but without greatly changing the EOs composition.

Compared with other extraction methods, IL-UMASDE gave the highest yields of CPT, HCPT, VCS-LT, EOs, and the shortest extraction time.

Table 3. Chemical composition of essential oils by GC-MS analysis.

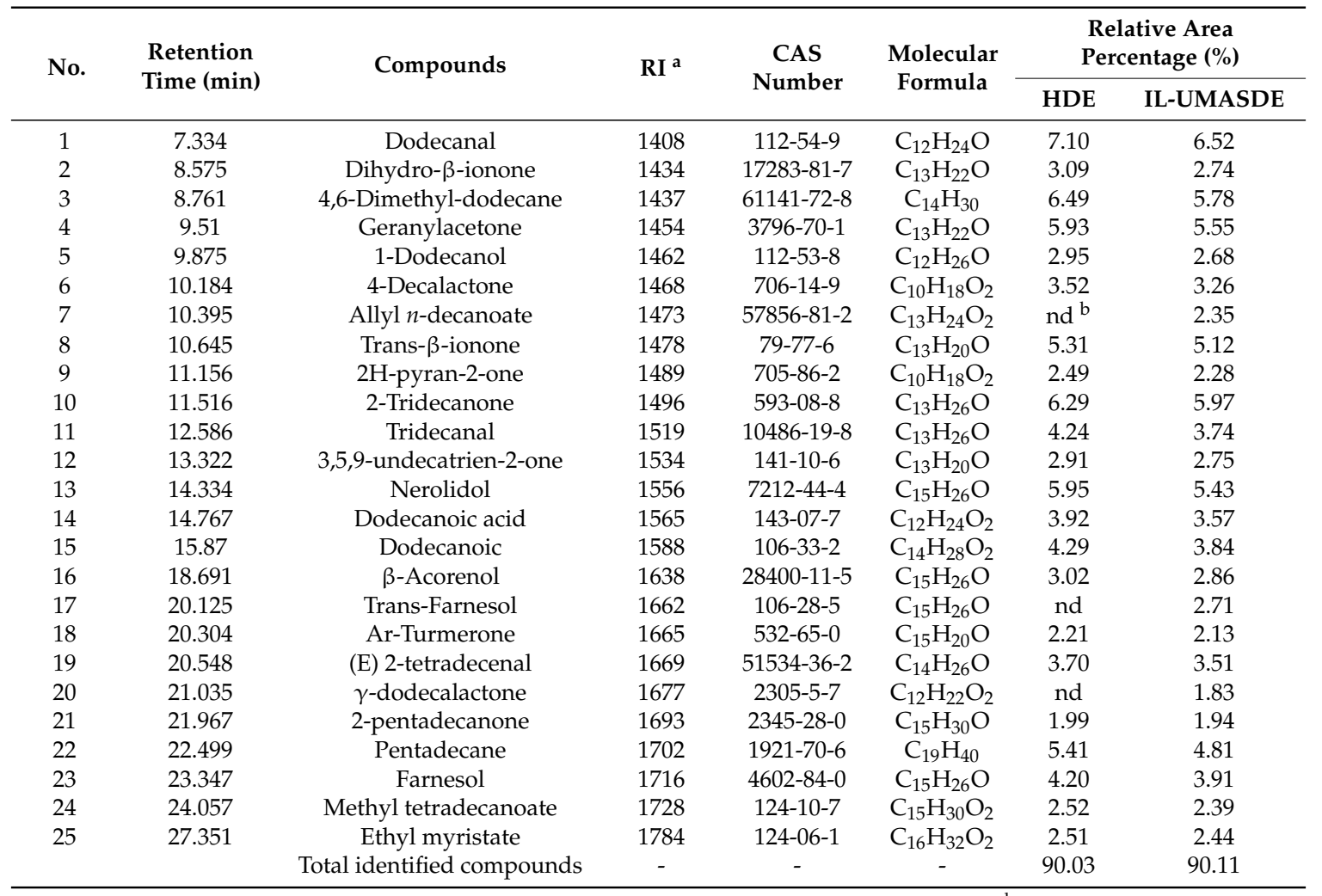

${ }^{\mathrm{a}}$ Retention indices relative to $\mathrm{C}_{7}-\mathrm{C}_{40} n$-alkanes on the HP-5MS capillary column; ${ }^{\mathrm{b}}$ Not detected.

In order to provide valuable information for engineering analysis and scale-up, first order kinetic equations were used to fit the extraction process (see Table 4). From the Table 4, we can see that the first order kinetic equation can describe the extraction process well, and the correlation coefficient range is $0.9769-0.9983$. From reaction rate constants $(K)$, compared to other extraction methods, IL-UMASDE can achieve the shortest equilibrium time for extraction of CPT, HCPT, VCS-LT, and EOs. 
Table 4. The reaction rate constants $(K)$ and correlation coefficients $\left(R^{2}\right)$ of first order equations for different extraction methods.

\begin{tabular}{|c|c|c|c|c|c|c|c|c|}
\hline \multirow{2}{*}{ Methods } & \multicolumn{2}{|c|}{$\mathrm{CPT}$} & \multicolumn{2}{|c|}{ HCPT } & \multicolumn{2}{|c|}{ VCS-LT } & \multicolumn{2}{|c|}{ EO } \\
\hline & $K\left(\min ^{-1}\right)$ & $R^{2}$ & $K\left(\min ^{-1}\right)$ & $R^{2}$ & $K\left(\min ^{-1}\right)$ & $R^{2}$ & $K\left(\min ^{-1}\right)$ & $R^{2}$ \\
\hline IL-UMASDE & 0.2187 & 0.9790 & 0.2111 & 0.9953 & 0.2033 & 0.9862 & 0.2397 & 0.9838 \\
\hline IL-MASDE & 0.0403 & 0.9840 & 0.0620 & 0.9944 & 0.0402 & 0.9839 & 0.0369 & 0.9769 \\
\hline IL-UAE & 0.0257 & 0.9967 & 0.0238 & 0.9964 & 0.0291 & 0.9983 & - & - \\
\hline Ethanol-UAE & 0.0311 & 0.9969 & 0.0341 & 0.9975 & 0.0326 & 0.9972 & - & - \\
\hline Ethanol-HRE & 0.0176 & 0.9816 & 0.0194 & 0.9908 & 0.0216 & 0.9963 & - & - \\
\hline Water-UMASDE & - & - & - & - & - & - & 0.0160 & 0.9915 \\
\hline Water-MASDE & - & - & - & - & - & - & 0.0311 & 0.9969 \\
\hline HDE & - & - & - & - & - & - & 0.0245 & 0.9977 \\
\hline
\end{tabular}

Most of the traditional methods require organic solvents, which resulting environmental pollution and potential health hazards to operators. On the contrary, ionic liquid is used as extraction solvent in our IL-UMASDE, ionic liquid vapor pressure is very low, so it can reduce the environmental pollution and health hazards to operators caused by solvent evaporation [22]. The ionic liquids are so expensive that its application was limited. Thus, the development of cheaper ionic liquids is the future research direction.

\section{Conclusions}

An efficient IL-UMASDE method was developed for extracting CPT, HCPT, VCS-LT, and EOs from Camptotheca acuminata Decne fruits. ILs are environmentally friendly solvents and have been successfully used in the IL-UMASDE process. The development of this method enables the simultaneous extraction of non-volatile compounds (CPT, HCPT, and VCS-LT) and volatile compounds (EOs). Single-factor experiments and CCD tests show that the optimum parameters are as follows: extraction solvent $0.75 \mathrm{M}\left[\mathrm{C}_{8} \mathrm{mim}\right] \mathrm{Br}$, extraction time $33.2 \mathrm{~min}$, liquid-solid ratio $13.7 \mathrm{~mL} / \mathrm{g}$, and microwave power $582 \mathrm{~W}$. Under the optimum conditions, the yields of CPT, HCPT, VCS-LT, and EOs were 2.463, 0.164, 0.297, and $0.793 \mathrm{mg} / \mathrm{g}$, respectively. Compared with other methods, the proposed approach gives higher yields of target compounds and a significantly shorter extraction time. In addition, the developed method accelerates the isolation of EOs from C. acuminata fruits without causing major changes in the EOs composition. The proposed green and effective IL-UMASDE method is therefore a promising technique for the simultaneous extraction of non-volatile and volatile compounds from other plants.

Acknowledgments: This work was financially supported by the Fundamental Research Fund for Central Universities (DL13CA06, 2572015EA04), the National Natural Science Foundation (31200478), and the Natural Science Foundation of Heilongjiang Province (C201412).

Author Contributions: Chunjian Zhao and Chunying Li conceived the underlying idea of the paper. Yukun Zhang, Xin He, Jingjing Zhang, and Wenyan Zhao contributed to the practical aspects of the research work; Yujie Fu, Yuangang Zu and Lei Yang analyzed the data; Yukun Zhang and Chunying Li wrote the manuscript.

Conflicts of Interest: The authors declare no conflict of interest.

\section{References}

1. Yang, L.; Li, X.; Zhao, C.; Li, J.; Zu, Y. Distribution of camptothecin and 10-hydroxycamptothecin in plant of Camptotheca acuminata Decne. Plant Physiol. Commun. 2008, 44, 873-876.

2. Wall, M.E.; Wani, M.; Cook, C.; Palmer, K.; McPhail, A.; Sim, G. Plant antitumor agents. I. The isolation and structure of camptothecin, a novel alkaloidal leukemia and tumor inhibitor from Camptotheca acuminata. J. Am. Chem. Soc. 1966, 88, 3888-3889. [CrossRef]

3. Hsiang, Y.; Hertzberg, R.; Hecht, S.; Liu, L. Camptothecin induces protein-linked DNA breaks via mammalian dna topoisomerase I. J. Biol. Chem. 1985, 260, 14873-14878. [PubMed] 
4. Palumbo, M.; Sissi, C.; Gatto, B.; Moro, S.; Zagotto, G. Quantitation of camptothecin and related compounds. J. Chromatogr. B Biomed. Sci. Appl. 2001, 764, 121-140. [CrossRef]

5. Lorence, A.; Nessler, C. Molecules of interest camptothecin, over four decades of surprising findings. Phytochemistry 2004, 65, 2735-2749. [CrossRef] [PubMed]

6. Ling, Y.; Perez-Soler, R.; Tseng, M. Effect of DNA topoisomerase I inhibitor, 10-hydroxycamptothecin, on the structure and function of nuclei and nuclear matrix in bladder carcinoma MBT-2 cells. Anticancer Res. 1993, 13, 1613-1617. [PubMed]

7. Zhang, X.; Qing, C.; Xu, B. Apoptosis induction and cell cycle perturbation in human hepatoma Hep G2 cells by 10-hydroxycamptothecin. Anticancer Drugs 1999, 10, 569-576. [CrossRef] [PubMed]

8. Zhang, X.; Qing, C.; Xu, B. Changes in the protein spectrum of mitochondria isolated from hydroxycamptothecin-treated hepatoma cells. Anticancer Drugs 2007, 18, 1045-1052.

9. Yin, F.; Hu, L. Two DNA topoisomerase I inhibitors from Camptotheca acuminata Decne. (Nyssaceae). Chin. J. Nat. Med. 2005, 3, 21-24.

10. Yuan, D.; Ma, B.; Wu, C.; Yang, J.; Zhang, L.; Liu, S.; Wu, L.; Kano, Y. Alkaloids from the leaves of Uncaria rhynchophylla and their inhibitory activity on NO production in lipopolysaccharide-activated microglia. J. Nat. Prod. 2008, 71, 1271-1274. [CrossRef] [PubMed]

11. Burt, A. Essential oils: Their antibacterial properties and potential applications in foods: A review. Int. J. Food Microbiol. 2004, 94, 223-253. [CrossRef] [PubMed]

12. Milhau, G.; Valentin, A.; Benoit, F.; Mallie, M.; Bastide, J.; Pelissier, Y.; Bessiere, J. In vitro antimicrobial activity of eight essential oils. J. Essent. Oil Res. 1997, 9, 329-333. [CrossRef]

13. Darokar, M.; Mathur, A.; Dwivedi, S.; Bhalla, R.; Khanuja, S.; Kumar, S. Detection of antibacterial activity in the floral petals of some higher plants. Curr. Sci. 1998, 75, 187-189.

14. Yu, T.; Wang, Y.; Yin, L.; Zu, Y. Study on the chemical composition of volatile oil from seeds of Camptotheca acuminate. Bull. Bot. Res. 1999, 19, 179-182.

15. Yu, M.; Wang, B.; Zhang, Y. The extraction, separation and purification of alkaloidsin the natural medicine. J. Chem. Pharm. Res. 2014, 6, 338-345.

16. Sharma, S.; Kumar, A.; Namdeo, A. Pharmacognostical and phytochemical analysis of Nothapodytes nimmoniana stem. Int. J. Pharm. Sci. 2012, 4, 455-459.

17. Shi, W.; Zu, Y.; Zhao, C.; Yang, L. Homogenated extraction of camptothecin from Camptotheca acuminata Decne. seed and leaves. J. For. Res. 2009, 20, 168-170. [CrossRef]

18. Zhang, J.; Yu, Y.; Liu, D.; Liu, Z. Extraction and composition of three naturally occurring anti-cancer alkaloids in Camptotheca acuminata seed and leaf extracts. Phytomedicine 2007, 14, 50-56. [CrossRef] [PubMed]

19. Fulzele, D.; Satdive, K. Comparison of techniques for the extraction of the anti-cancer drug camptothecin from Nothapodytes foetida. J. Chromatogr. 2005, 1063, 9-13. [CrossRef]

20. Ikeda, M. Public health problems of organic solvents. Toxicol. Lett. 1992, 64-65, 191-201. [CrossRef]

21. Naushad, M.; Alothman, Z.; Khan, A.; Ali, M. Effect of ionic liquid on activity, stability, and structure of enzymes: A review. Int. J. Boil. Macromol. 2012, 51, 555-560. [CrossRef] [PubMed]

22. Passos, H.; Freire, M.; Coutinho, J. Ionic liquid solutions as extractive solvents for value-added compounds from biomass. Green Chem. 2014, 16, 4786-4815. [CrossRef] [PubMed]

23. Ma, C.; Wang, S.; Yang, L.; Zu, Y.; Yang, F.; Zhang, L.; Zhang, Z. Ionic liquid-aqueous solution ultrasonic-assisted extraction of camptothecin and 10-hydroxycamptothecin from Camptotheca acuminata samara. Chem. Eng. Process. 2012, 57-58, 59-64. [CrossRef]

24. Zhang, Y.; Liu, Z.; Li, Y.; Chi, R. Optimization of ionic liquid-based microwave-assisted extraction of isoflavones from Radix puerariae by response surface methodology. Sep. Purif. Technol. 2014, 129, 71-79. [CrossRef]

25. Liu, Z.; Jia, J.; Chen, F.; Yang, F.; Zu, Y.; Yang, L. Development of an ionic liquid-based microwave-assisted method for the extraction and determination of taxifolin in different parts of Larix gmelinii. Molecules 2014, 19, 19471-19490. [CrossRef] [PubMed]

26. Li, C.; Lu, Z.; Zhao, C.; Yang, L.; Fu, Y.; Shi, K.; He, X.; Li, Z.; Zu, Y. Ionic liquid-based ultrasound/microwave-assisted extraction of 1,4-benzoxazin-3-one and 6-methoxy-benzoxazolin-2-one from maize (Zea mays L.) seedlings. J. Sep. Sci. 2015, 38, 291-300. [CrossRef] [PubMed] 
27. Hu, Y.; Kong, W.; Yang, X.; Xie, L.; Wen, J.; Yang, M. GC-MS combined with chemometric techniques for the X. Quality control and original discrimination of Curcumae longae rhizome: Analysis of essential oils. J. Sep. Sci. 2014, 37, 404-411. [CrossRef] [PubMed]

28. Liu, H.; Sun, Z.; Huang, C.; Lin, S.; He, D. The comparation of chemical component analysis about volatile oil from Cinnamomum cassia bark, Cinnamomum cassia Presl and Cinnamomum cassia leaf by gas chromatography-mass spectrometry. Food Res. Dev. 2010, 31, 144-147.

29. Cassel, E.; Vargas, R.; Martinez, N.; Lorenzo, D.; Dellacassa, E. Steam distillation modeling for essential oil extraction process. Ind. Crops Prod. 2009, 29, 171-176. [CrossRef]

30. Okoh, O.; Sadimenko, A.; Afolayan, A. Comparative evaluation of the antibacterial activities of the essential oils of Rosmarinus officinalis L. obtained by hydrodistillation and solvent free microwave extraction methods. Food Chem. 2010, 120, 308-312. [CrossRef]

31. Patra, J.; Kim, S.; Baek, K. Antioxidant and free radical-scavenging potential of essential oil from Enteromorpha linza L. prepared by microwave-assisted hydrodistillation. J. Food Biochem. 2015, 39, 80-90. [CrossRef]

32. Benkaci-Ali, F; Akloul, R.; Boukenouche, A.; Pauw, E. Chemical composition of the essential oil of Nigella sativa seeds extracted by microwave steam distillation. J. Essent. Oil Bear. Plants 2013, 16, 781-794. [CrossRef]

33. Gavrila, L.; Gavrila, A.; Ivopol, M.; Ivopol, G.; Popescu, M.; Mircioaga, N. Microwave assisted extraction of essential oils from enzymatically pretreated lavender (Lavandula angustifolia Miller). Cent. Eur. J. Chem. 2014, 112, 829-836.

34. Kraujalyte, V.; Leitner, E.; Venskutonis, P. Characterization of Aronia melanocarpa volatiles by headspace-solidphase microextraction (HS-SPME) simultaneous distillation/extraction (SDE) and gas chromatographyolfactometry (GC-O) methods. J. Agric. Food Chem. 2013, 61, 4728-4736. [CrossRef] [PubMed]

35. Chen, F.; Zu, Y.; Yang, L. A novel approach for isolation of essential oil from fresh leaves of Magnolia sieboldii using microwave-assisted simultaneous distillationand extraction. Sep. Purif. Technol. 2015, 154, 271-280. [CrossRef]

36. Zhao, C.; Li, Z.; Li, C.; Yang, L.; Yao, L.; Fu, Y.; He, X.; Shi, K.; Lu, Z. Optimized extraction of polysaccharides from Taxus chinensis var. mairei fruits and its antitumor activity. Int. J. Biol. Macromol. 2015, 75, 192-198. [CrossRef] [PubMed]

37. Zuo, Y. High-Performance Liquid Chromatography (HPLC): Principles, Procedures and Practices; Nova Science Publisher: New York, NY, USA, 2014.

38. Zhao, C.; Li, C.; Wang, L.; Zu, Y.; Yang, L. Determination of camptothecin and 10-hydroxycamptothecin in Camptotheca acuminata by LC-ESI-MS/MS. Anal. Lett. 2010, 43, 2681-2693. [CrossRef]

39. Adams, R. Identification of Essential Oil Components by Gas Chromatography/Mass Spectrometry; Allured: Carol Stream, IL, USA, 2007.

40. Bezerra, M.; Santelli, R.; Oliveira, E.; Villar, L.; Escaleira, L. Response surface methodology (RSM) as a tool for optimization in analytical. Talanta 2008, 76, 965-977. [CrossRef] [PubMed]

41. Bica, K.; Gaertner, P.; Rogers, R. Ionic liquids and fragrances-Direct isolation of orange essential oil. Green Chem. 2011, 13, 1997-1999. [CrossRef]

42. Fukaya, Y.; Hayashi, K.; Wada, M.; Ohno, H. Cellulose dissolution with polar ionic liquids under mild conditions: Required factors for anions. Green Chem. 2008, 10, 44-46. [CrossRef]

43. Huddleston, J.; Visser, A.; Reichert, W.; Willauer, H.; Broker, G.; Rogers, R. Characterization and comparison of hydrophilic and hydrophobic room temperature ionic liquids incorporating the imidazolium cation. Green Chem. 2001, 3, 156-164. [CrossRef]

44. Pinkert, A.; Marsh, K.; Pang, S.; Staiger, M. Ionic liquids and their interaction with cellulose. Chem. Rev. 2009, 109, 6712-6728. [CrossRef] [PubMed]

45. Remsing, R.; Swatloski, R.; Rogers, R.; Moyna, G. Mechanism of cellulose dissolution in the ionic liquid 1-n-butyl-3-methylimidazolium chloride: A 13C and 35/37Cl NMR relaxation study on model systems. Chem. Commun. 2006, 12, 1271-1273. [CrossRef] [PubMed]

46. Lou, Z.; Wang, H.; Zhu, S.; Chen, S.; Zhang, M.; Wang, Z. Ionic liquids based simultaneous ultrasonic and microwave assisted extraction of phenolic compounds from burdock leaves. Anal. Chim. Acta 2012, 716, 28-33. [CrossRef] [PubMed] 
47. Ma, W.; Lu, Y.; Hu, R.; Chen, J.; Zhang, Z.; Pan, Y. Application of ionic liquids based microwave-assisted extraction of three alkaloids $\mathrm{N}$-nornuciferine, $\mathrm{O}$-nornuciferine, and nuciferine from lotus leaf. Talanta 2010, 80, 1292-1297. [CrossRef] [PubMed]

48. Henderson, L.; Byrne, N. Rapid and efficient protic ionic liquid-mediated pinacol rearrangements under microwave irradiation. Green Chem. 2011, 13, 813-816. [CrossRef]

49. Zuo, Y.; Zhang, K.; Wu, J.; Rego, C.; Fritz, J. An accurate and non-destructive GC method for determination of cocaine on US paper currency. J. Sep. Sci. 2008, 31, 2444-2450. [CrossRef] [PubMed]

(C) 2016 by the authors; licensee MDPI, Basel, Switzerland. This article is an open access article distributed under the terms and conditions of the Creative Commons Attribution (CC-BY) license (http:/ / creativecommons.org/licenses/by/4.0/). 